Microsoft Teams) due to the COVID-19 pandemic, which enabled virtual participation. We used the research questions generated to inform future quality improvement work. We asked staff to complete a feedback survey to determine their views of the process.

Results We have conducted 30 journal club meetings, which have generated 124 research questions. Thirteen meetings were virtual. We have conducted quality improvement work using these research questions to improve clinical care. Nineteen staff (representing five clinical sites) completed feedback. The feedback was positive, with participants stating that the journal club was educational, clinically relevant and enjoyable. The main problem identified by participants were technological issues relating to participating in the virtual meetings.

Conclusion/Discussion We have demonstrated how a palliative care journal club can be used to improve clinical care in a hospice. Our experience can be used by other palliative care settings to engage staff in research and improve care for those with serious illness.

\section{0-12 HOSPICE HERITAGE STORIES: MAKING EVERY MEMORY MATTER}

Sarah Beer. St Helena Hospice, Colchester, UK

10.1136/spcare-2021-Hospice.11

Background As we approached a key anniversary, we found our timeline lacked real people's stories of our hospice's origin. The number of surviving founders was dwindling so we risked losing first-hand accounts. We also respected the value of our current stories. We applied successfully to The National Lottery Heritage Fund to support the project.

Aims Preservation of our hospice heritage through recording memories of people involved from its inception in 1979 to the Royal opening of our day centre in 1988, and to add to historical research of the hospice movement. By sharing past and present stories throughout the project, and curating the collection for an online archive, an exhibition at the hospice, and a mobile exhibition including to local areas of deprivation; we are aiming to engage, educate, inspire, and dispel fear about hospice care. Aimed to record 20 heritage stories and 15 stories of current patients, families, staff and volunteers.

Methods Conduct and record oral history interviews digitise images and VHS film footage; use digital and traditional media to invite reminiscence and share stories; build heritage area on website; present the heritage stories through exhibition; deposit oral histories with records office.

Results Currently in the last stages of the project, preparing the collection for: online and physical exhibitions; book of heritage stories; podcast series; repository. Throughout the project social media engagement with our heritage stories is showing that we are inspiring pride in our heritage; opportunity for reminiscence; inclusive access for different audiences. Recorded 21 heritage and $30+$ current stories. Data from digital analytics, exhibition visitor numbers and feedback will be collected for evaluation.

Conclusions Heritage and current stories are generating positive hospice public relations and marketing opportunities; preserving memories before they are lost to benefit wider historical research of the hospice movement; giving people a voice.
Parallel Session 4.1 - Enhancing support in the community (Thursday 4 November, $13: 30-14: 45)$

\section{0-13 INTEGRATED CARE - MAKING POSITIVE IMPACTS WHEN IT MATTERS MOST}

${ }^{1}$ Kay Greene, ${ }^{2}$ Debbie Martin. 'Mary Ann Evans Hospice, Nuneaton, UK; ${ }^{2}$ South Warwickshire NHS Foundation Trust, North and South Warwickshire, UK

10.1136/spcare-2021-Hospice. 12

We have been working together in a blended way with a common vision to ensure palliative and end of life care services provided in the home setting, inclusive of care homes, truly makes a difference to people known to be palliative regardless of the stage of their disease. Our integrated, 24/7 rapid responsive care service, is not defined by an illness time point.

Our vision was to provide an enhanced specialised team together. This team would do their utmost to ensure that any calls for help resulted in people remaining being cared for in their own home setting wherever possible - a wraparound service, ultimately avoiding unnecessary acute care admissions.

Patients, family members, friends or professionals simply have to dial our direct mobile number and circa 90\% of those calls for help will receive a visit from our team in person within 30 minutes of making their call overnight, 365 days a year.

In the first full operational year (2018-19) of the service, 823 patients received 1479 visits between $8 \mathrm{pm}-8 \mathrm{am}$. As the service extended to 24 hours in 2020-2021, our visit count reached 3628, with only 16 of these visits resulting in an acute admission for clinical need. Our team reported that 2216 of the 3628 visits, without their input, most likely the outcome would have been transmission to local A\&E.

In addition to people being able to receive care where they prefer to; our service costs us between $£ 50-60$ per hour to provide - considerably less than an onward ambulance journey and potential acute hospital admission.

Working as a large NHS Foundation Trust - over 5000 employees and a small independent charity community hospice with just over 60 employees brought us several challenges as well as benefits. The benefits of integration for our local population have by far outweighed any challenges which we overcame together and will continue to do so going forwards.

\section{0-14 CREATION OF A VIRTUAL WARD: A RESPONSE TO COVID-19}

Sheona Evangeli, Nikki Tuff, Matt Sweeting, Sue Griffith, Alison Stevens, Alison Gray. Farleigh Hospice, Chelmsford, UK

\subsection{6/spcare-2021-Hospice. 13}

Background With a second wave of COVID-19 peaking in mid-December 2020, one hospice closed its inpatient unit to allow clinical staff to be utilised to greater effect in the community. This approach had been used during the first wave of the pandemic, with good effect, allowing more referrals and 
more patients to be cared for in their place of choice. However, for a very small number of complex patients, the lack of inpatient facilities had proved problematic. To avoid this consequence during the second wave, a new plan to open a virtual ward, staffed by some of the inpatient team, was devised. Aim To ensure that dying patients with complex needs were given equitable and appropriate care whilst the inpatient unit was closed.

Method Clinical staff were once more re-located to the community teams, but this time with 24-hour provision of nursing care, rather than the usual four times daily visits. Medications were administered in a more timely way, and delivery of personal care was given at the patient's convenience, rather than set times, with increased support for families. Closer liaison with the multi-disciplinary team (MDT) also improved the patient experience, with daily MDT discussion.

Results Eight patients who required complex medical intervention, were admitted to other local hospices. However, 47 patients were admitted to the virtual ward, averaging 8.6 admissions per month. Identification of the last weeks of life was greatly improved by the internal referral process, reflected in an average length of stay of 7 days (range 3-13 days).

Conclusion By offering complex care to people at end of life in their own homes, this approach fulfilled the ideal criteria of 'providing everyone the right care, from the right person at the right time' and reduced prior inequality of care provision (Thomas, 2021).

\section{0-15 WORKING COLLABORATIVELY TO IMPROVE END OF LIFE DOMICILIARY CARE}

${ }^{1}$ Sue Griffith, ${ }^{2}$ Isabel Richmond, ${ }^{3}$ Melanie Harwood, ${ }^{4}$ Jenny Peckham. ${ }^{1}$ Farleigh Hospice, Chelmsford, UK; ${ }^{2}$ St Francis Hospice, Romford, UK; ${ }^{3}$ St Luke's Hospice, Basildon, UK; ${ }^{4}$ Essex County Council, Chelmsford, UK

10.1136/spcare-2021-Hospice.14

Background Audits and Care Quality Commission intelligence revealed a knowledge and skills gap for domiciliary carers giving end-of-life care. This resulted in end-of-life patients in Essex not always dying in the place of their choice, with frequent inappropriate 999 calls and transfer to hospital.

Aim This project was devised to offer unified end-of-life care teaching to domiciliary care providers across Essex, to upskill carers and create supportive links with council and local hospices. This ultimately would improve the care given to those at end-of-life, reduce unnecessary hospital admissions and support the confidence and comfort of carers.

Methods A three-day course was created by the three main hospices in the area working collaboratively with the local council. Funding was sourced by the council, so that participants could attend free-of-charge. The course was delivered in all three areas, covering the same end-of-life care material and addressing all six Ambitions for end of life care (National Palliative and End of Life Care Partnership, 2015; National Palliative and End of Life Care Partnership, 2021). The course also addressed the Care Quality Commission's inspection Key Lines of Enquiry and fulfilled requirements of latest national guidance (Thomas, 2021).
Results The teaching has reached approximately 650 carers over the last two years, through a cascade method of teaching. Pre- and post-learning questionnaires demonstrated increased knowledge and confidence for all participants. Furthermore, $80 \%$ of attendees reported cascading the knowledge acquired to colleagues, with $60 \%$ reporting a marked improvement in attitude of staff toward giving end-of-life care. Telephone calls to local hospice helplines increased, with a parallel reduction in 999 calls, meaning that those patients received more appropriate care at home. Links to local hospices have been strengthened, and participating care agencies have received recognition for their improved work, with one agency gaining 'Outstanding' in their inspection, and a care sector award for their end-of-life care.

Conclusion This joint teaching project has improved end-of-life care given to people across a whole county, and also offers a model for others to replicate.

\section{0-16 SUPPORTING CARERS TO ADMINISTER END OF LIFE SUBCUTANEOUS MEDICATION IN THE COMMUNITY}

Sheila Popert, Debbie Robson. Prospect Hospice, Swindon, UK

10.1136/spcare-2021-Hospice. 15

The aim of this initiative was to facilitate timely symptom relief at the end of life for patients in their own homes (Healy, Israel, Charles et al., 2018). By safely training family carers to administer subcutaneous medications, patients receive symptom relief without delay and family members report feeling able to support their loved one in their moment of need (Anderson \& Kralik, 2008). This change not only enables effective, responsive symptom control, but also patient choice, carer involvement and preferred place of death. A registered nurse or doctor is responsible for ensuring this is carried out safely with training, reviews and monitoring (Healy, Israel, Charles, 2013).

Quality improvement methodology was used to provide a structure in which to safely roll out the initiative. During the early phases Plan Do Study Act (PDSA) cycles were used to evaluate success and identify opportunity for improvement after each new referral to the service. This included reviewing carer feedback at every stage to inform the evolution of the initiative, as part of the PDSA process.

This initiative is becoming well-embedded at Prospect Hospice and we have had fantastic feedback from those involved. We are now keen to support the roll out of this approach to the wider local Integrated Care System (ICS). Not only does it bring benefit to patients and family carers, it also releases valuable time and resource for the Hospice to direct elsewhere.

For example, thanks to this initiative one patient supported over a total of 13 days was able to remain at home, with support from her family, and died peacefully with appropriate medication administration. We calculated that the total number of community visits saved was 39 , equating to approximately $3.5 \mathrm{hrs}$ of nursing time per day, including travel. Training was provided to the family carers when the patient was an inpatient at the Hospice, and the family had access to a $24 \mathrm{hr}$ helpline to use as needed. This is just one of many examples. 